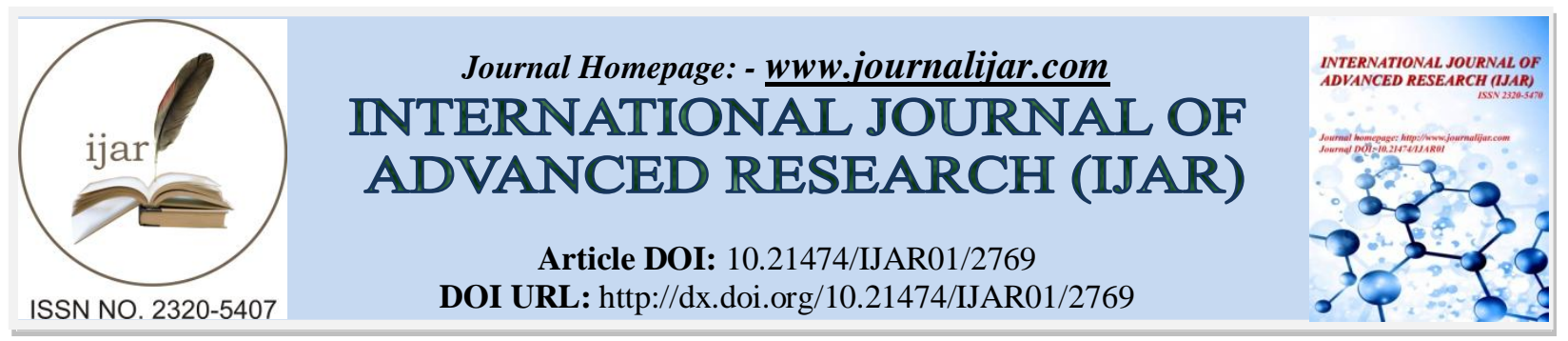

RESEARCH ARTICLE

\title{
MANNU BHANDARI KI KAHANIYO ME NARI : DASHA YAUM DISHA
}

\section{Dr. Praveen Deshmukh.}

Assistant Professor \& HOD of Hindi Ghulam Nabi Azad Arts, Commerce \& Science College, Barshitakli, DistAkola (Maharashtra) 444001.

\section{Manuscript Info}

\section{Manuscript History}

Received: 15 November 2016

Final Accepted: 17 December 2016

Published: January 2017

\section{Abstract}

हिन्दी साहित्य अंतर्गत लेखिकाओं द्वारा रचित साहित्य में मन्न भण्डारी द्वारा रचित साहित्य अपनी एक अलग अमीट छाप छोड़ता है। इनके साहित्य का मुख्य केन्द्रबिन्दु नारी रही है। समाज में नारी के प्रति सामाजिक दृष्टिकोण को उजागर करना लेखिका का महत्वपूर्ण दृष्टिकोण रहा है। मन्नू भण्डारी एक सशक्त कहानीकार के रूप में उभरकर सामने आयी है। उनका समग्र साहित्य ही समाज में घटित महत्वपूर्ण तथ्यों को उजागर करता है। मन्नुजी द्वारा रचित कहानियॉ सामाजिक यथार्थ को प्रस्तुत करती हे,तथा नारी के विभिन्न पक्षों को हमारे समक्ष उपस्थित करती है। जहॉ शोषण दिखाई देता है वहॉ मन्नू भण्डारी विरोध दर्शाती है। मानवीय गुणों की दृष्टि से यदि विचार करे तो हमारे ध्यान में आता है कि पुरुष की तुलना में नारी अधिक मानवीय है। मानव जाति की सभ्यता एंव संस्कृति का परिचायक या विकास का मूलाधार नारी रही है। मन्नू भण्डारी कहानीयॉ कहानी विधा की एक प्रमुख और विशेष रही है। उनकी कहानियों का मूलभूत आधार मौलिकता से परिपूर्ण दिखायी देता है।

Copy Right, IJAR, 2016,. All rights reserved.

\section{प्रस्तावना}

भारतीय संस्कति में पुरुष प्रधानता प्रमुखता रही है। जितना महत्व पुरुष को हे,उतना महत्व स्त्री को नहीं मिल पाया। यही इस समाज का सबसे बड़ा दूर्भाग्य रहा है। यह एक निर्विवाद सत्य है। जिसे अनदेखा नहीं किया जा सकता। भारतीय नारी अपने अनुभवों का सच पूरी तरह बोलने की हिम्मत जुटा नहीं पायी है। पुरुष प्रधान समाज ने नारी को विभिन्न बंधनों में बॉधकर रखा। वह नारियों को मात्र घरेलू श्रमशक्ति और भोगविलास की वस्तु बनाए रखने के लिए सदा प्रयत्नशील रहा है। नारी का दमन और शोषन इस दुनिया की पुरानी,गहरी और सबसे जटिल व्यवस्था है जिसकी जड़े धर्म,संस्कृति और परम्पराओं में धॅसी हुई है। इन जटिल विचारधारा को चिरकर महिलाऍ अपने विचारों को तथा अपने मनके भावों को तथा धीरे-धीरे अपनी बिखरी हुई और असंघटित हालात से निकलकर अपनी आवाज को सुनाने लगी है।इसीलिए हमें महिलाएँ घरेलू बंधनों से निकलकर सामाजिक,राजनीतिक,साहित्यिक और सास्कृंतिक कार्यों में अपनी अमीट छाप छोड़ती दिखाई देती है। नारी की पुरुष प्रधान समाज में अपने अस्तित्व की तलाश ही नारी का अपने अधिकार एंव् अहसास को प्रदर्शित करता है।

मन्नू भण्डारी के कहानी में नारी

साहित्य की मुख्यधारा पुरुष-वर्चस्व से निर्मित है,ऐसे कृतिकारों ने नारी को जिन बिम्बों की रचना की,भोगलालसा,स्त्री-दमन आदि के पोषक है। मन्नू भण्डारी की रचनाशीलता का प्राणतत्व भी भारतीय नारी की मुक्ति है। सदियों से जो बंदी बनकर अपना जीवन मात्र जी रही है, ऐसी नारियों को जीवन का वास्तविक और सही रास्ता दर्शाने का प्रयास या फिर कहे कि उस ओर देखने का दृष्टिकोण दिखाने में जो अहम् और महत्वपूर्ण भूमिका दर्शायी ऐसे नारियों में मन्नू भण्डारी की रचनाऍ अपना महत्वपूर्ण योगदान रखती है। मन्नू भण्डारी मध्यवर्ग में जीवन जी रही नारी को घुटन से मुक्त करना चाहती है।

बदलते परिवेश में नारियों को सजग और अपने अस्तित्व को लेकर तथा नारी जीवन में नई चुनौतियों और नई दिशाओं के प्रति, नई-नई समस्याओं को लेकर तथा सामाजिक बदलाव की सजगता की आवश्यकता है। मन्नू भण्डारी का जन्म किसी मेट्रों शहर में नहीं बल्कि एक साधारण और छोटे गॉव में हुआ। अपने जन्म को लेकर स्वंय मन्नू भण्डारी जी ने अपनी आत्मकथा 'एक कहानी यह भी' में बताया है-"जन्मी तो मध्य-प्रदेश के भानपुरा गॉव में थी, लेकिन मेरी यादों का सिलसिला शुरू होता है अजमेर के ब्रहमपुरी मोहल्ले के उस दो मंजिले मकान से जिसकी ऊपरी मंजिल में पिता जी का साम्राज्य था, जहॉ वे निहायत अव्यवस्थित ढंग से फैली बिखरी पुस्तकों-पत्रिकाओं और अखबारों के बीच या तो कुछ पढ़ते रहते थे या फिर 'डिक्टेशन' देते थे।" 1

Corresponding Author:- Dr. Praveen Deshmukh.

Address:- Assistant Professor \& HOD of Hindi Ghulam Nabi Azad Arts, Commerce \& Science College, Barshitakli, Dist-Akola (Maharashtra) 444001. 


\section{दशा एव्ं दिशा}

तात्पर्य यह है कि भारतीय समाज में प्रधानता पुरुष वर्ग की ही है,और रही है। इस सत्य को या इस वास्तविकता को नकारा नहीं जा सकता। मन्नूजी ने विपूल साहित्य की रचना कर इस साहित्य द्वारा समाज में एक नवचेतना जागृत करने का महान कार्य किया है। विशेषता: मानवीय जीवन से संबंधीत सभी मूल्य उनकी रचनाओं में प्रमुखता से दिखायी देते है।'मूल्य' समाज के जीवन में सामाजिक,धार्मिक,आर्थिक,नैतिक पृष्ठीूमि के लिए एक महत्वपूर्ण वैचारिक इकाई है, उनका समग्र साहित्य विशेषता: नारी जीवन के सभी पक्षों को उजागर करता है। इनकी रचनाओं में जो नारी का स्वरुप चित्रित किया गया है वह हमें समाज में भी दिखाई देता है।

दर्शनशास्त्र में जगत,जीव एंव प्रकृति के साथ मानव एंव मानवीय मूल्यों पर भी विशेष बल दिया गया है। जैसे- " भारतीय दर्शन में चरम मूल्यों पर अधिक बल दिया जाता रहा है, जबकि 'पश्चिम में विघटन की स्थिति आने पर ही मूल्यों की चर्चा आरम्भ हुई।" 2

अर्थात मूल्य ही हमारी सबसे बड़ी धरोवर होती है, जिसके सहारे हमारा जीवन-यापन होता है। मन्नू भण्डारी की कहानियों में हमें मूल्य चेतना दिखायी देती है। जैसे मन्नू भण्डारी की 'चश्में' कहानी है, जिसमें प्रेम पर आधारित एक आदर्शवादी मूल्यों की स्थापना करती है। तो दूसरी कथा प्रेम के आदर्शवादी मूल्यों का खण्डन करती दिखाई देती है। जैसे- " लीला चाहती है कि वह अपने कातिंकारी पति को हॉसते हूए विदा दे, किन्तु अन्तिम घड़ियों में वह रो पड़ती है। फिर भी एक अलौकिक सन्तोष और तृप्ति की भावना उसके मन में है कि मरने से पहले वह अपने पति को अपना सब कुछ दे सकी। अपने आपकों लुटाकर उसने उसे सुखी बनाया, धनी बनाया।" 3

उसीप्रकार उनकी 'तीन निगाहों की एक तस्वीर' कहानी यौन जीवन का चित्रण मनोविज्ञानिक ढंग से प्रस्तुत करती है। इस कहानी में शरीर को महत्वपूर्ण बताया गया। तथा शरीर की भूख 'काम' के आगे समाज के नैतिक मूल्यों को थोथा साबित किया गया है। हर स्त्री को ऐसा लगता है कि अपने पति से काम-वासना की तृप्ति हो। इस कहानी की नायिका 'दर्शना' भी यौन भावनाओं से त्रस्त है। उसका पति शादी के दिन से ही टी.बी. के कारण बीमार। वह हरीश के प्रति लगाव रखती है। जिससे वह घरवालों से दूर और अंत में दूनिया से चली जाती है। तीन निगाहों की तस्वीर' कहानी की दर्शना भी ऐसी स्त्री है,जो पति द्वारा घर से निष्कासित किए जाने के बावजूद नौकरी करके एकाकी जीवन-यापन करती है।

आज समाज में भी ऐसे कई उदाहरण मिलते है जो अपनी काम-पूर्ति हेतू कभी-कभी गलत रास्ता अपना लेते है, जिससे परिवार उथल-पुथल होते हुए दिखाई देते है। लोकजीवन के सघन कटू पारिवारिक,सामाजिक,सच्चाई को मन्नू भण्डारी ने अपनी कहानीयों के विषय बनाये। 'मै हार गई' सन 1957 में प्रकाशित प्रथम कहानी संग्रह अर्तंगत 'मै हार गई' इस कहानी में राजनीति का वास्तविक चेहरा दिखाया। राजनीति पर तीखा व्यंग्य करने वाली श्रेष्ठ कहानी है। जिसमें लेखिका के मित्र ने राजनीति पर जो सवाल खड़े किए थे, उन सवालों पर करारा जवाब हेतु तथा उड़ायी गयी मज़ाक का कड़ा उत्तर देने हेतु लेखिका की असफलता। अंतः सहर्ष स्वीकार करना की मैं हार गई। डॉ. सुखवीरसिंह लिखते हैं,-“" छोटे से कैनवास पर सामाजिक ढॉचे के बीच पनपने वाले कटु सत्य की अभिव्यक्ति जिस सांकेतिक रूप में इस कहानी में हुई है, उसमें निश्चित ही पंरपरागत नैतिक अवधारणाओं के प्रति नकारात्मक रूख स्पष्ट हो जाता है।" 4

इस कहानी से यह स्पष्ट हो जाता है कि आज के इस आधुनिक, भूमणड़लीकरण,नीजिकरण, वैश्विकरण के युग में आदर्श नेता की कल्पना करना और उसमें भी सृजन करना मुश्किल है। इस कहानी के माध्यम से वर्तमान युग में राजनेताओं को लक्ष्य किया गया है। अपने व्यक्तिगत स्वार्थ से और सम्पन्न तथा विकासीनता से जकड़े हुए है।

पितृ प्रधान समाज में 'अकेली' कहानी की सीमा बुआ बेटे के आकर्मिक अवसान एंव पति के सन्यासी हो जाने के बाद नाना प्रकार के मानव सर्जिट कटू अनुभवों से जूझती है। " मुझे क्या बावली ही समझ रखा है जो बिना बुलाए चली जाऊॅगी? अरे वह पड़ोस वालों की नंदा अपनी ऑखों से बुलावे की लिस्ट में नाम देखकर आई है। और बुलावेंगे क्यों नहीं? शहरवालों को बुलावेंगे और समधियों को नहीं बुलावेंगे क्या?-5

मन्नू भण्डारी पूर्ववर्ती एंव समकालीन नारी मनोविज्ञान का बराबर ध्यान अपनी कहानियों में रखती दिखायी देती है। लेखिका के अनुसार आज दास प्रथा, सामंती प्रथा एंव पूजीवादी प्रथा से कहीं ज्यादा खतरनाक वैश्विकरण,निजीकरण,उदारीकरण एंव विश्वग्राम है। 'खोटे सिक्के' कहानी में खन्ना साहब मजदूरों से पूरा काम लेते है। दो प्राध्यापिकाओं के साथ बीस-बाइस छात्राऍ टकसाल देखने जाती है तो खन्ना साहब जिस भाव से लड़कियों से मिलते है वह भाव प्राध्यापिकाओं के साथ नहीं रहता है।" काम करने। अरे एक ही जगह खाली होती है तो पचासों टूट पड़ते हैं। आप जानती नहीं हमारे देश में इन्सान का जान बड़ी सस्ती है।" 6

मन्नू भण्डारी के अनुभव संसार की व्यापकता और वैविध्यता कबिल-ए-तारीफ है। उनकी यह व्यापकता हर कहानी में देखने को मिलती है। नारी मनोविज्ञान की अनछुई मनः स्थितियों को मन्नू भण्डारी भलीभॉति जानती पहचानती है। मन्नू भण्डारी की कहानी 'स्त्री सुबोधिनी' एक अविवाहित उन्मुक्त यौन सम्बन्ध रखने वाली नारी की कहानी है। कहानी की नायिका अपने बॉस शिंदे से यौन सम्बन्ध रखती है। उनके अनुसार प्रेम कतई कैरियर ओरिएंटेड़ नहीं है। मात्र शिंदे वैवाहिक व्यक्ति है, वह केवल शौकिया तौर पर उससे यौन सम्बन्ध रखता है, उससे महसूस होता है कि " प्रेम का बीज मन और शरीर का पवित्र भूमि से नहीं ठेठ घर परिवार की उपजाऊ भूमि में ही फलता-फूलता है।" 7

मन्नू भण्डारी की कहानी का दर्द समाज में भी मौजूद है। ऐसी कहानियॉ समाज में भी घटित होती दिखाई देती है। कहानी पारिवारिक मूल्यों की हिमायती है। सामाजिक मूल्य परिवर्तन में विशेष रूप से परिवार,प्रेमविषयक धारणाऍ आदि के परिणामस्वरूप मूल्य परिवर्तन की अटलता,शाश्वत मूल्यों को सुरक्षित रखने का प्रयास भी किया जाना आवश्यक है।आज हालात बिल्कुल विपरित दिखाई देते है। वास्तव में यह समय मूल्यहीनता का है। सामाजिक,धार्मिक और सांस्कृतिक स्तर पर मनुष्य के व्यवहार में मूल्यहीनता आ गयी है। मूल्यहीनता की स्थिति परिवार के विघटन, दाम्पत्यों सम्बन्धों में बिखराव,उन्मुक्त-यौन संबंध आदि सब यह उसी के परिणाम हैं। स्वाधीनोंत्तर हिन्दी कथा साहित्य को जिन लेखिकाओं ने समृध्द किया है,उनमें मन्नू भण्डारी का अग्रनीय रहा है। मन्नू भण्डारी की रचनाओं में मानवीय संवेदनाओं के उफान के साथ नारी संघर्ष और शोषण के विरुद्ध स्वर तथा नारी मन की करुण व्यथा है। उनके पात्र नैतिकता और अनैतिकता के प्रश्नों से न उलझकर परिस्थितियों के अन्तर्द्वन्द्व को ही विशेष रूप से रेखांकित करते है।

मन्नू भण्डारी द्वारा लिखित कहानी'रानी मॉ का चबूतरा' में गुलाबों सामाजिक प्राणी होने के कारण कई कठिनाईयों से जूझती दिखाई देती है। स्वंय भूखी रहकर बेटी के लिए चूड़ियॉ खरीदती और बेटे को शिशु सुरक्षा केन्द्र में भर्ती कराती है। 'मजबूरी' कहानी में पात्र बूढ़ी अम्मा में मात् वात्सल्य,त्याग और कर्तव्यनिष्ठा जैसे जीवन मूल्य दृष्टिगत होते है। "दो कलाकार" कहानी की नायिका अरुणा में त्याग,समर्पण और समाजसेवा के भाव लक्षित होते है।'नकली हीरे' कहानी में इन्दु ऐसी नारी है, जो अपनी धनवान बहन द्वारा दिया गया हीरे का हार स्वीकार नहीं करती। 'नशा' 
कहानी की आनन्दी में आत्म-सन्मान कूट-कूट कर भरा है।'बंद दरवाजों के साथ कहानी में विवाह का बदला हुआ स्वरुप दिखाई देता है। कहानी की मंजरी को अपने पति के पूर्व जीवन के बारे में पता चलते ही वह उसे त्याग कर चली जाती है और दिलीप नामक अन्य युवक से शादी करके अपना नया जीवन आरम्भ करती है। 'यही सच'कहानी की दीपा में स्थायी प्रेम लक्षित नहीं होता। वह कभी संजय की ओर आकर्षित होती है तो कभी निशीथ की ओर।

आज के समाज में व्यक्ति अपने संस्कारों भूलकर नारी पर अत्याचार,बलात्कार, उसका शोषण कर उसे अनुचित रूप से स्रित्रिों को अपने मोह-जाल में फसाने की चेष्टा करता हैं। मन्नू भण्डारी की कहानियों में जो सच दिखायी देता है, वह आज समाज में घटित होता दिखाई देता है। अंधकार,बलात्कार,स्त्री के साथ अनुचित व्यवहार, उसपर अत्याचार कर उसके मौलिक अधिकारों पर हनन।'वर्तमान समाज में स्त्रियॉ उपेक्षित और एक अर्थहीन जीवन को अभिशप्त हैं। चारित्रिक दृष्टि से रस्खलित पुरुषों की वृत्ति तो दुषित है ही किन्तु स्त्रियों की आत्मबल क्षीणता भी निर्दोंष नहीं, अन्यथा जैसी प्रताड़नापूर्ण घृणित घटनाऍ देखने,सुनने और पढ़ने में आती हैं, सम्भवतः न होती।" 8

ऊँचाई इस कहानी में लेखिका ने ऐसी नारी को रूपायित किया है। जो एक ही समय पत्नी और प्रेमिका दोनों भूमिकाओं का निर्वाह निर्ट्हन्द्व भाव से करती है। नारी के विवाहोत्तर-संबंध को सहज मानने का, विवाहिता नारी का नया नैतिक बोध इसमें दर्शाया गया है। नैतिक नियम पुरुष और स्त्री दोनों को समान होने चाहिए। पुरुष के लिए अलग और स्त्रि के लिए भिन्न। ऐसा नहीं होना चाहिए। शिवानी की निर्भीकता और स्पष्टवादिता से पति निर्णय बदलता है। जिस समर्पण में वासना नहीं होती वह पाप नहीं होता ऐसे विचार शिवानी के होते है। इस संबंध में डॉ कपूरिया का कथन विशेष उल्लेखनीय है-" एक प्यार की स्वीकृति के लिए दूसरे प्यार का झूठा सिदध करना आवश्यक नहीं है। कहीं ऐसी भी ऊँचाई है कि जहॉ शरीर का एक से अधिक व्यक्तियों के साथ संबंध बहुत नगण्य होकर दिखाई दे।"'9

शिवानी को विवाह बाहय संबंध रखने में न कोई पाप बोध होता है न ही कोई तनाव, बल्कि एक साथ पत्नी और प्रेमिका का दायित्व निर्वाह करने का संतोष होता है। इस सन्दर्भ में वह कहती है-“" नारी एक साथ एक से अधिक पुरुषों से प्रेम करती हुई उनसे शारीरिक संबंधों का निर्वाह करते हुए उस ऊँचाई पर रह सकती है, जिसे नैतिक ऊँचाई चाहे न भी कहा जाए,किन्तु वह उसके स्वतंत्र अस्तित्व एंव व्यक्तित्व की ऊँचाई अवश्य है।" 10

शिवानी सामान्य परिपाटी से अलग जीवन जीने में विश्वास रखती है,पवित्रता और नैतिकता का संबंध शरीर के साथ होता ही नहीं ऐसा विचार वह निर्भिकता से रखती है। वह सामान्य परिपाटी से निकलकर वह वैवाहिक जीवन के परंपरागत बंधनों को चुनौती देती है,तथा विद्रोह कर वह अति आधुनिक रूप सामने लाती है। परम्परा का घोर तिरस्कार आधुनिकता की देन हैं। भूमण्ड़लीकरण, निजीकरण, औद्योगीकरण और आधुनिकीकरण के फलस्वरुप परिवारों का स्वरुप टूटने लगा है। इस संदर्भ में डॉ. ब्रज मोहन शर्मा विशेष उल्लेखनीय कथन कहते है कि-"चिरकाल से पुरुष के हथकंड़ों की शिकार और अपने अधिकारों से वंचित नारी आज पूर्णतः जागरूक है।"11

परम्परा को नकारनेवाली नारी की सूरत को मन्नू भण्डारी ने दीवार बच्चे और बरसात,यही सच है, ऊँाई आदि कहानियों के द्वारा स्पष्ट दिखाया है। बरसात कहानी अंतर्गत बरसात के बहाव से दीवार का ढह जाना वास्तव में परम्परागत रुढ़ियों से नारी के मुक्त होने की सूचना ही देता है। एक एक पल की सार्थकता से जीवन की सम्पूर्णता को रूप देना क्षणबोध की विशेषता है।

\section{निष्कर्ष}

मन्नू भण्डारी की कहानियॉ समाज के समक्ष एक वास्तविक सच उजागर करती है। उनके कहानी के विभिन्न पात्र समाज में चल रहे द्वन्द्व को अपने चरित्रों के जरिये उजागर करते है। मन्नू भण्डारी रचित कहानियॉ मध्यवर्गीय जीवन को संयुक्त परिवार का विघटन एंव जीवन्त चित्रण,अभिव्यक्त मध्यवर्गीय नारी पुरुष,परिवार समाज के निम्न लिखित रूप उभरकर सामने आए। संयुक्त परिवार का विघटन,अणु परिवार का उदय,दाम्पत्य विघटन,स्त्री-पुरुष सम्बन्धों में द्वन्द्व,पुरुष प्रधान समाज व्यवस्था,राजनीतिक आदर्शों की निरर्थकता,नैतिक मूल्यों का -हास,आर्थिक तनाव,तथा पूँजीपतियों की हदयहीनता। मन्नू भण्डारी की रचनाओं में मानवीय संवेदनाओं के उफान के साथ नारी संघर्ष और शोषण के विरुद्ध स्वर तथा नारी मन की करुण व्यथा है।

\section{सन्दर्भ ग्रंथ-सूचि}

डॉ. षीना ईप्पन- मन्नू भण्डारी का रचनासंसार,जवाहर पुस्तकालय,हिन्दी पुस्तक प्रकाशक एंव वितरक,सदर बाजार,मथुरा,संस्करण-सन् 2009,पृ-19-20 डॉ. ओम्प्रकाश नायर- मन्नू भंडारी की कहानियों में मूल्य चेतना,विद्या प्रकाशन,सी-449,गुजैनी, कानपुर-22,संस्करण-प्रथम,2010,पृ-11

वही -पृ-55

डॉ. किशोर सिंह राव,डॉ. मीरा ए. सक्सेना- मन्नू भण्डारी की कथा यात्रा,ज्ञान प्रकाशन, $128 / 90$,जी,ब्लाक किदवई नगर, कानपुर,संस्करण-प्रथम,2010,पृ-97

वही- पृ-50

वही- पृ-51

डॉ. भारती शेळके- महिला रचनाकारों की कहानियों में जीवन मूल्य, विद्या प्रकाशन, सी-449,गुजैनी, कानपुर-22,संस्करण-2014,पृ-58

डॉ. राजनारायण पाण्डेय- हिन्दी कथा साहित्य में नारी शोषण,उत्कर्ष पब्लिशर्स एण्ड डिस्ट्रीब्यूटर्स,ए-685,आवास विकास हंसपुरम,कानपुर,संस्करण-प्रथम,2013,पृ-119

डॉ. सौ. मंगल कप्पीकेरे- साठोत्तरी हिन्दी लेखिकाओं की कहानियों में नारी,विकास प्रकाशन,311 सी.विश्व बैंक,बर्रा,कानपुर,संस्करण-प्रथम,2002,पृ-142 वही-पृ-142

डॉ. किशोर सिंह राव,डॉ. मीरा ए. सक्सेना- मन्नू भण्डारी की कथा यात्रा,ज्ञान प्रकाशन, $128 / 90$,जी,ब्लाक किदवई नगर, कानपुर, संस्करण-प्रथम,2010,पृ-97 